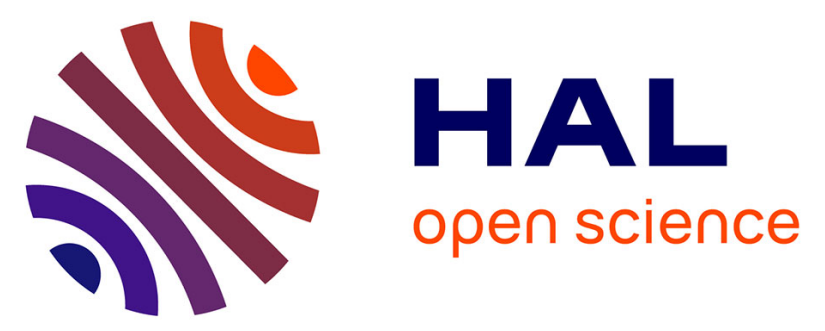

\title{
Should sensory impairment be considered in frailty assessment? A study in the GAZEL cohort
}

Morgane Linard, Marie Herr, Philippe Aegerter, Sébastien Czernichow, Marcel Goldberg, Marie Zins, Joël Ankri

\section{To cite this version:}

Morgane Linard, Marie Herr, Philippe Aegerter, Sébastien Czernichow, Marcel Goldberg, et al.. Should sensory impairment be considered in frailty assessment? A study in the GAZEL cohort. Journal of Nutrition, Health \& Aging, 2016, 20 (7), pp.714 - 721. 10.1007/s12603-015-0651-4 . inserm01802816

\section{HAL Id: inserm-01802816 https://www.hal.inserm.fr/inserm-01802816}

Submitted on 29 May 2018

HAL is a multi-disciplinary open access archive for the deposit and dissemination of scientific research documents, whether they are published or not. The documents may come from teaching and research institutions in France or abroad, or from public or private research centers.
L'archive ouverte pluridisciplinaire $\mathbf{H A L}$, est destinée au dépôt et à la diffusion de documents scientifiques de niveau recherche, publiés ou non, émanant des établissements d'enseignement et de recherche français ou étrangers, des laboratoires publics ou privés. 


\section{Should sensory impairment be considered}

\section{in frailty assessment? A study in the GAZEL cohort}

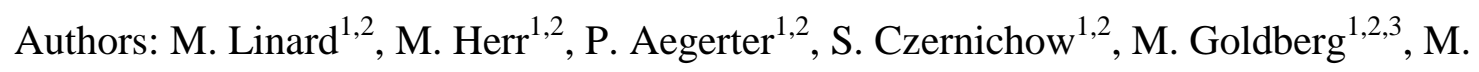
$\operatorname{Zins}^{1,2,3}$, J. Ankri ${ }^{1,2}$

1 INSERM, VIMA: Aging and chronic diseases. Epidemiological and public health approaches, U1168, F-94807, Villejuif, France

${ }^{2}$ UVERSUSQ, UMR-S 1168, Université Versailles St-Quentin-en-Yvelines, France

${ }^{3}$ UMS 011, INSERM-UVSQ, Villejuif, France

Correspondence: Pr. Joël Ankri

INSERM UMR 1168 : «Vieillissement et Maladies chroniques : approches épidémiologique et de santé publique », Université Versailles St-Quentin-en-Yvelines

Centre de Gérontologie, 49, rue Mirabeau, 75016 PARIS, FRANCE

Tel: +33144963205

Fax: +33144963146

joel.ankri@spr.aphp.fr 


\section{ABSTRACT}

Objectives: The assessment of sensory difficulties is sometimes included in the screening of frailty in ageing population. This study aimed to compare the prevalence of frailty and associated risk of adverse outcomes depending on whether sensory difficulties participated in the definition of frailty.

Design: Prospective cohort study - GAZEL cohort

Setting: France

Participants: The 13,128 subjects who completed a questionnaire in 2012.

Measurements: According to the Strawbridge questionnaire, subjects were considered frail if they reported difficulties in two domains or more among physical, nutritive, cognitive and sensory domains. The risk of adverse health outcomes was assessed by using and logistic regression models (hospitalisations, onset of difficulty in performing movements of everyday life) and multivariate Cox proportional hazards models (mortality).

Results: Mean age was $66.8+/-3.4$ years and $73.8 \%$ were males. The prevalence of frailty varied from 4.4 to $14.2 \%$ depending on whether the sensory domain was excluded or included. During follow-up, 182 deaths (1.4\%), 479 hospitalisations (3.6\%) and 703 cases of disability $(8.0 \%)$ were observed. Both definitions of frailty predicted the onset of difficulties to perform everyday movements, with 2 to 3 -fold increase in the risk. The inclusion of the sensory domain in the definition made frailty predictive of hospitalisations (Odds Ratio 1.31 [1.01-1.70]) but the association with mortality was only observed when sensory difficulties were ignored (Hazard Ratio 2.28 [1.32-3.92]).

Conclusion: The inclusion of a sensory domain into a frailty screening instrument has a major impact in terms of prevalence and modifies the risk profile associated with frailty. In order to 
develop the use of frailty screening instruments in clinical practice, further researches will need to carefully evaluate the impact on risk prediction of the different domains involved.

Key words: aged, definition, frailty, sensory difficulties, predictive value 


\section{INTRODUCTION}

During the last decade, frailty has raised increasing interest among researchers and geriatricians. Frailty is defined as "a consequence of age-related decline in many physiological systems, which collectively results in vulnerability to sudden health status changes triggered by minor stressor events" (1). Main health outcomes reported are falls, hospitalisations, disability, institutionalization and death (2). Frailty is recognized as a useful concept because it improves the understanding of the heterogeneity of vulnerability in old people (3). Moreover, frailty is assumed to be a reversible status, which can take advantage of early preventive interventions and reduce adverse health outcomes and health care costs.

Despite its growing recognition, there is still no consensual definition of frailty. Two main approaches co-exist: the frailty phenotype and the cumulative deficit model. The frailty phenotype published in 2001 by Fried and colleagues is defined as a clinical syndrome in which three or more of the following criteria are present: unintentional weight loss, selfreported exhaustion, weakness (grip strength), slow walking speed and low physical activity (4). According to the cumulative deficit model, frailty can be assessed by adding deficits in many physiological systems into a summary score called frailty index $(5,6)$.

Depending on their purpose, on the target population, and on the data available, different screening instruments for frailty have been proposed (2). The choice of the domains that should be included into screening instruments for frailty is still under debate (7) and experts pointed out the need to determine "the contribution to frailty from other clinical domains not currently included in broad definitions that may enhance predictive value" (8). A systematic review of existing screening instruments for frailty published by Sternberg et al. indicates that sensory impairment is part of 6 out of the 22 frailty screening instruments (2), which is probably explained by the fact that sensory impairment was shown to be a risk factor 
for falls, institutionalization, disability and reduced quality of life (9-11). Nevertheless, few studies have investigated the relationship between sensory impairment and frailty (12-14) and, to our knowledge, none has investigated the impact of adding a sensory domain into a frailty score, in terms of prevalence and predictive ability.

In a large cohort of ageing people in France, this study aimed to compare two definitions of frailty differing by the inclusion or not of a sensory domain, with regards to the prevalence of frailty, the associated risk of adverse outcomes and its predictive ability. Frailty was assessed by using the Strawbridge questionnaire (15) and adverse outcomes of interest were onset of difficulty in performing everyday life movements, hospitalisation and death.

\section{MATERIAL AND METHODS}

\section{Study design and participants}

This work is based on the data from the GAZEL study, a prospective cohort that began in 1989 and is still ongoing. Participants were recruited among the 150,000 employees of France's national electricity and gas utility (Eléctricité de France - Gaz de France, EDFGDF). Details concerning the study design have been described elsewhere (16). Briefly, 20,625 employees (5,614 women and 15,011 men aged 35-50 years) accepted to participate. Each year, participants were invited to complete a postal questionnaire including a large set of items dealing with health status, lifestyle, socioeconomic and occupational factors. Data were also collected from national registers and personal and medical departments of EDF-GDF. A total of 18,426 participants (89.3\%), aged between 58 and 73, were still followed in the cohort in 2012. That year, the Strawbridge questionnaire was added to the annual questionnaire to assess frailty in the ageing cohort. Our study population consisted of the subjects included in the GAZEL cohort who completed the frailty assessment in 2012. 


\section{$\underline{\text { Frailty assessment }}$}

According to Strawbridge et al. (15), the frailty assessment was based upon 16 items gathered in four domains. Four items assessed physical domain (sudden loss of balance, weakness in the arms, weakness in the legs, get dizzy when stand up quickly), two items assessed nutritive domain (unexplained weight loss, loss of appetite) and four items assessed cognitive domain (difficulty paying attention, difficulty finding the right word, difficulty remembering things, forgetting where put something). The six other items assessed sensory domain: three items assessed vision problems (difficulty reading newspapers, difficulty recognizing a friend across the street, difficulty reading signs at night) and three hearing problems (hearing over the phone, hearing a normal conversation, hearing a conversation in a noisy room).

Scores for the six items of the sensory domain ranged from 1 to 4 , with $1=$ no difficulty, 2 = little difficulty, 3 = some difficulty and $4=$ great deal of difficulty. Scores for the other ten items were rated differently, with: $1=$ rarely or never had the problem in the last 12 months, $2=$ sometimes had the problem, $3=$ often had the problem and $4=$ very often had the problem. Participants who scored 3 or 4 in one item were considered to have difficulty in this item.

Subjects were considered frail if they reported difficulty in 2 domains or more.

\section{Covariates}

Data were collected about socio-demographic characteristics (age, gender, socioeconomic position, family situation and education), health status (reported body mass index, self-perceived health, depression, chronic diseases and hospitalisations) and behaviours (tobacco and alcohol consumption). Self-perceived health was rated with a Likert scale 
including 8 levels grouped by two to create a variable with 4 levels (very poor/poor/good/very good). Social situation was rated with a Likert scale including 10 levels grouped to create a variable with 3 levels (disadvantaged, normal, comfortable). The emotional status was assessed using the French version of CES-D scale (Center for Epidemiologic Studies Depression scale) (17). Subjects were considered as depressed if their score was $\geq 17$ for men and $\geq 23$ for women. A comorbidity score was created using the presence or absence of 7 selfreported diseases: cancer, diabetes, hypertension, lung disease, heart disease, stroke and muscular or articular pain. Three levels of comorbidity were defined, depending on the number of self-reported diseases: $0 / 1 / \geq 2(18)$.

\section{Outcomes}

The longitudinal design of the study enabled to have information about hospitalisations, onset of difficulty in performing movements of everyday life, and mortality. Hospitalisations were documented with a question included in the 2013 questionnaire: “During the past 12 months, have you been hospitalized?" The onset of difficulty in performing movements of everyday life was defined as a positive answer to the question "Do you have difficulty performing some movements of everyday life?" in 2013 while there was no reported difficulty in 2012. Information concerning mortality was obtained from EDFGDF personal department; the median of the follow-up was 2.2 years.

\section{$\underline{\text { Statistical analysis }}$}

Characteristics of the study population were described using prevalence for categorical variables and mean +/- standard deviation (SD) for continuous variables. The prevalence of frailty was compared according to the following definition: 
- FrailtyS+: at least 2 domains impaired among 4 (physical, nutritive, cognitive, sensory);

- FrailtyS-: at least 2 domains impaired among 3 (physical, nutritive, cognitive).

Factors associated with frailty were identified using logistic regression models. The variables introduced into the models were those associated with frailty with a p-value $<0.20$ in bivariate analysis, as well as those commonly found associated with frailty in the literature. The final models were obtained by eliminating variables associated with outcomes with a pvalue $>0.05$.

The risk of adverse health outcomes in relation to frailty was assessed by using multivariate Cox proportional hazards models (mortality) and logistic regression models (hospitalisations and onset of difficulty in performing movements of everyday life). The variables introduced into the models were selected as described above. The predictive ability of the different definitions was compared by computing the area under the curve (AUC) (hospitalisation and onset of difficulty in performing movements of everyday life) and the Harrell's C statistic (mortality).

The results are presented with adjusted Hazard Ratio (aHR) and Odds Ratio (aOR) with $95 \%$ confidence intervals (95\% CI). Analyses were performed using Stata ${ }^{\circledR}$ software, version 13.0.

\section{RESULTS}

\section{$\underline{\text { Population }}$}

Among the 18,426 subjects who were invited to complete the questionnaire in 2012, 13,587 subjects returned the questionnaire (participation rate $=73.7 \%$ ). Compared to nonparticipants, subjects who returned the questionnaire in 2012 were more likely to be men 
(73.7\% versus $68.2 \%, \mathrm{p}<0.001)$, were slightly older $(+0.4$ year on average, $\mathrm{p}<0.001)$ and more educated (high level of education: $18.8 \%$ versus $13.2 \%, \mathrm{p}<0.001$ ).

Because of critical missing data regarding frailty, 459 subjects were excluded from the analysis that was finally carried out in 13,128 subjects (flow-chart in Figure 1). Compared to people with missing data, those included in the analysis were younger (-1.0 year on average, $\mathrm{p}<0.001)$, more educated $(\mathrm{p}=0.027)$, and less likely to have started another professional activity after retirement from EDF-GDF ( $\mathrm{p}<0.001)$. However, there was no difference regarding gender or comorbidity score (Table 1).

The study population was mostly composed of males (73.8\%), of retired people (88.1\%), and of people living in couple (83.2\%). Mean age was $66.8+/-3.4$ years $(\mathrm{min}=58$, $\max =73)$. Among them, $41.2 \%$ reported one health problem $(n=5,406)$ and $42.2 \%$ reported 2 diseases or more $(n=5,537)$. The main reported diseases were articular or muscular pain $(66.3 \%, n=8,706)$, hypertension $(30.3 \%, n=3,978)$ and lung disease $(17.7 \%, n=2,319)$. Characteristics of the participants are further described in Table 1.

\section{Prevalence of frailty}

Table 2 shows the distribution of reported problems or difficulties in the items included in the Strawbridge questionnaire. Sensory difficulties were the most frequently reported $(41.6 \%)$, followed by cognitive, physical and nutritional impairments $(12.6 \%, 10.3 \%$ and $2.0 \%$, respectively). Among the study population, 4,772 subjects $(36.4 \%)$ reported hearing problems and 1,798 (13.7\%) visual problems. Men were more likely to experience sensory difficulties than women $(43.2 \%$ versus $37.2 \%$, $\mathrm{p}<0.001)$. Nevertheless, visual problems were more frequent in women $(21.9 \%$ versus $10.8 \%, \mathrm{p}<0.001)$ whereas hearing problems were more frequent in men $(40.0 \%$ versus $26.2 \%, \mathrm{p}<0.001)$. 
The prevalence of frailtyS+ was $14.2 \%(95 \%$ CI: 13.6\%-14.8\%) $(n=1,866)$. Most of the subjects identified as frailS+ $(93.4 \%)$ reported visual or hearing problems. When excluding the sensory domain (frailtyS-), the prevalence of frailty was reduced to $4.4 \%$ (95\% CI: $4.1 \%-4.8 \%)(n=577)$. In both cases, the prevalence of frailty increased with age and was higher among women (Table 3).

\section{Factors associated with frailty}

Factors associated with frailty in multivariate analysis are presented in Table 4. Whatever the definition of frailty, the main factors associated with frailty were female gender, old age, a very poor self-perceived health, depression, thinness (body mass index $\leq 18.5$ $\mathrm{kg} / \mathrm{m}^{2}$ ) and higher level of comorbidity. Associations with variables indicating a poor health status were enhanced when frailty was defined without sensory impairment (frailtyS-). For instance, a very poor self-perceived health was more strongly associated with frailtyS- (OR $5.92[3.60-9.71])$ than with frailtyS+ (OR 3.40 [2.12-5.47]). High education level, low social situation and high alcohol consumption were only associated with frailtyS+.

\section{Prediction of adverse health outcomes}

Among the study population, 182 subjects (1.4\%) died within the follow-up, 479 (3.6\%) were hospitalized between 2012 and 2013, and 703 subjects (8.0\%) developed difficulties in performing everyday life movements.

FrailtyS+ was not significantly associated with mortality whereas frailtyS- more than doubled the risk of dying within the follow-up (Table 5). Both definitions identified people at increased risk for onset of difficulties in performing movements of everyday life whereas frailtyS+ was the only one significantly associated with hospitalisations during the 12 months following the frailty assessment. 
The discriminative ability of the definitions was not influenced by the frailty definition. Values of the Harrell's C statistics and AUC were comprised between 0.64 and 0.77, with the higher values being observed for mortality.

We ensured that each domain of frailty was significantly associated with at least one outcome, independently of the other domains (Table 5). Risk factors for mortality were physical and nutritive impairments. The sensory domain was the only one predicting hospitalisations. As to incident difficulties in performing movements of everyday life, they were related to the presence of physical, cognitive and sensory impairments.

\section{$\underline{\text { DISCUSSION }}$}

\section{Main findings}

This study assessed frailty through impairments in four domains that were the physical, nutritive, cognitive and sensory domains. The prevalence of frailty - defined as an impairment in at least two domains - varied substantially depending on whether the sensory domain participated in the identification of frailty or not, from $4.4 \%$ when it was excluded from the definition of frailty to $14.2 \%$ when it was included. Of note, most subjects identified as frailS+ reported visual or hearing difficulties (93.4\%). In addition to an increase in the number of people identified as frail, the inclusion of a sensory domain in the definition of frailty led to identify people relatively healthier, with lower risks of adverse health outcomes.

\section{$\underline{\text { Strengths and limits }}$}

Main strengths of this study are its prospective design, its large sample size and the broad scope of the data collected. The study population was selected among all the regions of France and represented various socio-professional categories. The participation rate was 
noteworthy considering the 25 years follow-up and only few subjects were excluded because of missing data or loss of follow-up. Nevertheless, results should be interpreted with caution considering the age of the study population and the large proportion of males. Though the study sample was relatively young, the prevalence of sensory difficulties was similar to estimations in people aged 65-84 years in France (namely $11 \%$ for visual problems and $28 \%$ for hearing problems) (19). Considering gender differences in frailty, this study may not be the ideal setting to explore them. For instance, the low number of death in women $(n=29)$ did not allow us to perform the survival analysis by gender. Elsewhere, the assessment of frailty did not include physical measures. Self-reported data enabled us to assess frailty in thousands of people but their accuracy can be questioned (particularly in ageing people who could present memory impairment).

\section{Impact of the sensory domain on the prevalence and factors associated with frailty}

Compared to other studies that used the Strawbridge questionnaire, we found a lower prevalence of frailty (14.2\% versus $21 \%$ in the study by Matthews et al. (20) and $26 \%$ in original paper by Strawbridge et al. (15)), probably because of the younger age of our study population. Further comparisons with the literature are uncertain considering the variability of the prevalence of frailty according to the definition used. In a literature review published in 2012, the prevalence of frailty was estimated between 4.0 and $59.1 \%$ depending on the scores used (21).

In our study, there was a 3 -fold increase in the prevalence of frailty when sensory impairment was considered in the frailty assessment (from $14.2 \%$ to $4.4 \%$ ). This result shows that the very composition of the scores has a major impact on the prevalence of frailty and it reaffirms the need of further researches to study the relevance of each domain to get a consensual definition. 
Despite differences in the prevalence of frailty according to the definition used, factors associated with frailty are relatively constant across studies. Thus, we found the same factors than those described in the literature: age, gender, number of pathologies, self-perceived health, depression, and body mass index $(22,23)$. In addition, we confirmed the role of socioeconomic factors, also previously suggested in other studies (24-26).

\section{Impact of the sensory domain on the prediction of adverse health outcomes}

It's widely accepted that frailty is a risk factor for death (27), hospitalisations and disability (4). Nevertheless, the Strawbridge definition of frailty predicted hospitalisations and incident difficulties in everyday movements, but not mortality in our study. Matthews et al (20) found that the Strawbridge definition of frailty was associated with mortality only when self-reported cognitive problems were replaced by cognitive tests. Here, we have shown that the exclusion of the sensory domain from the definition enabled to identify people with a higher risk of mortality.

\section{$\underline{\text { Relevance of the frailty assessment }}$}

When analysing the prediction of adverse health outcomes, the values of the AUC and Harrell's C statistics were fair, shedding light on the limited discriminative ability of the models. These results are not surprising in view of literature, where these statistics range between 0.58 and 0.78 for similar outcomes (28) (29) (30). This lack of discriminative ability is mainly related to the high rates of false positive. Our findings, together with results of previous studies, confirm that current frailty screening tools are not enough powerful to implement public health policies. Thought frailty is a risk factor for adverse health outcomes, it is not sufficient to be a good diagnostic tool (31). 
More broadly, this study raises the question of the relevance of the concept of frailty compared to the separate assessment of physical, nutritional, cognitive, and sensory impairments. Each type of impairment can already be prevented, diagnosed and treated, independently from the assessment of frailty. The identification of the frailty status based on the presence of difficulties in 2 domains or more could result in the underestimation of health care needs in subjects with only one domain impaired, thus identified as non-frail. Nevertheless, the implementation of frailty measures in clinical practice may help the generalization of standardized geriatric evaluations that could otherwise be neglected.

Thus, the choice to include or not sensory impairment into the frailty definition should depend on the objective of the frailty assessment. If the aim is to screen subjects with difficulties, the frailtyS+ definition seems to be the most interesting definition because it includes a wider range of age-related problems. But if emphasis is given to the prediction of health adverse outcomes, the frailtyS- definition may be more performant.

\section{CONCLUSION}

The inclusion of a sensory domain into a frailty definition has a major impact on the number of subjects identified, on the severity of their health problems, and on the risk of adverse outcomes. It allows for a broader assessment of age-related difficulties but does not improve the discriminative ability of the frailty concept. In order to develop the use of frailty screening instruments in clinical practice, further researches will need to carefully evaluate the impact on risk prediction of the different domains involved.

\section{Ethics statement}


The Gazel Cohort Study was approved by the Commission Nationale de l'Informatique et des Libertés and the Ethics Evaluation Committee of INSERM. Participants provided written informed consent.

\section{Conflict of interest:}

Dr. Linard has nothing to disclose.

Dr. Herr has nothing to disclose.

Dr Zins has nothing to disclose.

Dr. Goldberg has nothing to disclose.

Dr. Czernichow reports personal fees from novo, personal fees from MSD, personal fees from servier, personal fees from Lilly, personal fees from covidien, outside the submitted work; . Dr. Aegerter has nothing to disclose.

Dr. Ankri has nothing to disclose.

\section{$\underline{\text { References }}$}

1. Clegg A, Young J, Iliffe S, Rikkert MO, Rockwood K. (2013). Frailty in elderly people. Lancet, 381(9868), 752-62. doi: 10.1016/S0140-6736(12)62167-9

2. Sternberg SA, Wershof Schwartz A, Karunananthan S, Bergman H, Mark Clarfield A. (2011). The identification of frailty: a systematic literature review. Journal of the American Geriatrics Society, 59(11), 2129-38. doi: 10.1111/j.1532-5415.2011.03597.x

3. Bergman H, Ferrucci L, Guralnik J, Hogan DB, Hummel S, Karunananthan S, et al. (2007). Frailty: an emerging research and clinical paradigm--issues and controversies. The journals of gerontology Series A, Biological sciences and medical sciences, 62(7), 731-7. 
4. Fried LP, Tangen CM, Walston J, Newman AB, Hirsch C, Gottdiener J, et al. (2001). Frailty in older adults: evidence for a phenotype. The journals of gerontology Series A, Biological sciences and medical sciences, 56(3), M146-56.

5. Mitnitski AB, Mogilner AJ, Rockwood K. (2001). Accumulation of deficits as a proxy measure of aging. TheScientificWorldJournal, 1, 323-36. doi: 10.1100/tsw.2001.58

6. Rockwood K, Song X, MacKnight C, Bergman H, Hogan DB, McDowell I, et al. (2005). A global clinical measure of fitness and frailty in elderly people. CMAJ : Canadian Medical Association journal = journal de l'Association medicale canadienne, 173(5), 489-95. doi: 10.1503/cmaj.050051

7. Gobbens RJ, Luijkx KG, Wijnen-Sponselee MT, Schols JM. (2010). Towards an integral conceptual model of frailty. The journal of nutrition, health \& aging, 14(3), 175-81. 8. Walston J, Hadley EC, Ferrucci L, Guralnik JM, Newman AB, Studenski SA, et al. (2006). Research agenda for frailty in older adults: toward a better understanding of physiology and etiology: summary from the American Geriatrics Society/National Institute on Aging Research Conference on Frailty in Older Adults. Journal of the American Geriatrics Society, 54(6), 991-1001. doi: 10.1111/j.1532-5415.2006.00745.x

9. Dalton DS, Cruickshanks KJ, Klein BE, Klein R, Wiley TL, Nondahl DM. (2003). The impact of hearing loss on quality of life in older adults. The Gerontologist, 43(5), 661-8. 10. Jin YP, Wong DT. (2008). Self-reported visual impairment in elderly Canadians and its impact on healthy living. Canadian journal of ophthalmology Journal canadien d'ophtalmologie, 43(4), 407-13. doi: 10.3129/i08-077

11. Deshpande N, Metter EJ, Bandinelli S, Lauretani F, Windham BG, Ferrucci L. (2008). Psychological, physical, and sensory correlates of fear of falling and consequent activity restriction in the elderly: the InCHIANTI study. American journal of physical medicine \& 
rehabilitation / Association of Academic Physiatrists, 87(5), 354-62. doi:

10.1097/PHM.0b013e31815e6e9b

12. Doba N, Tokuda Y, Goldstein NE, Kushiro T, Hinohara S. (2012). A pilot trial to predict frailty syndrome: the Japanese Health Research Volunteer Study. Experimental gerontology, 47(8), 638-43. doi: 10.1016/j.exger.2012.05.016

13. Kamil RJ, Li L, Lin FR. (2014). Association between hearing impairment and frailty in older adults. Journal of the American Geriatrics Society, 62(6), 1186-8. doi:

$10.1111 /$ jgs. 12860

14. Ng TP, Feng L, Nyunt MS, Larbi A, Yap KB. (2014). Frailty in Older Persons: Multisystem Risk Factors and the Frailty Risk Index (FRI). Journal of the American Medical Directors Association, 15(9), 635-42. doi: 10.1016/j.jamda.2014.03.008

15. Strawbridge WJ, Shema SJ, Balfour JL, Higby HR, Kaplan GA. (1998). Antecedents of frailty over three decades in an older cohort. The journals of gerontology Series B, Psychological sciences and social sciences, 53(1), S9-16.

16. Goldberg M, Leclerc A, Bonenfant S, Chastang JF, Schmaus A, Kaniewski N, et al. (2007). Cohort profile: the GAZEL Cohort Study. International journal of epidemiology, 36(1), 32-9. doi: 10.1093/ije/dyl247

17. Morin AJ, Moullec G, Maiano C, Layet L, Just JL, Ninot G. (2011). Psychometric properties of the Center for Epidemiologic Studies Depression Scale (CES-D) in French clinical and nonclinical adults. Revue d'epidemiologie et de sante publique, 59(5), 327-40. doi: 10.1016/j.respe.2011.03.061

18. Alvarado BE, Zunzunegui MV, Beland F, Bamvita JM. (2008). Life course social and health conditions linked to frailty in Latin American older men and women. The journals of gerontology Series A, Biological sciences and medical sciences, 63(12), 1399-406.

19. Danet S. (2011). L'Etat de Santé de la Population en France. DREES. 
20. Matthews. (2004). Use of a questionnaire to screen for frailty in the elderly : an exploratory study. Aging clinical and experimental research.

21. Collard RM, Boter H, Schoevers RA, Oude Voshaar RC. (2012). Prevalence of frailty in community-dwelling older persons: a systematic review. Journal of the American Geriatrics Society, 60(8), 1487-92. doi: 10.1111/j.1532-5415.2012.04054.x

22. Santos-Eggimann B, Cuenoud P, Spagnoli J, Junod J. (2009). Prevalence of frailty in middle-aged and older community-dwelling Europeans living in 10 countries. The journals of gerontology Series A, Biological sciences and medical sciences, 64(6), 675-81. doi:

10.1093/gerona/glp012

23. Theou O, Brothers TD, Pena FG, Mitnitski A, Rockwood K. (2014). Identifying common characteristics of frailty across seven scales. Journal of the American Geriatrics Society, 62(5), 901-6. doi: 10.1111/jgs.12773

24. Szanton SL, Seplaki CL, Thorpe RJ, Jr., Allen JK, Fried LP. (2010). Socioeconomic status is associated with frailty: the Women's Health and Aging Studies. Journal of epidemiology and community health, 64(1), 63-7. doi: 10.1136/jech.2008.078428

25. Peek MK, Howrey BT, Ternent RS, Ray LA, Ottenbacher KJ. (2012). Social support, stressors, and frailty among older Mexican American adults. The journals of gerontology Series B, Psychological sciences and social sciences, 67(6), 755-64. doi: 10.1093/geronb/gbs081

26. Sirven N. (2013). Une analyse des déterminants socio-économiques de la fragilité des personnes âgées à partir des données de panel et rétrospectives de SHARE. Document de travail N52 IRDES.

27. Shamliyan T, Talley KM, Ramakrishnan R, Kane RL. (2013). Association of frailty with survival: a systematic literature review. Ageing research reviews, 12(2), 719-36. doi: 10.1016/j.arr.2012.03.001 
28. Bouillon K, Sabia S, Jokela M, Gale CR, Singh-Manoux A, Shipley MJ, et al. (2013). Validating a widely used measure of frailty: are all sub-components necessary? Evidence from the Whitehall II cohort study. Age, 35(4), 1457-65. doi: 10.1007/s11357-012-9446-2 29. Sourial N, Bergman H, Karunananthan S, Wolfson C, Payette H, Gutierrez-Robledo LM, et al. (2013). Implementing frailty into clinical practice: a cautionary tale. The journals of gerontology Series A, Biological sciences and medical sciences, 68(12), 1505-11. doi: $10.1093 /$ gerona/glt053

30. Pijpers E, Ferreira I, Stehouwer CD, Nieuwenhuijzen Kruseman AC. (2012). The frailty dilemma. Review of the predictive accuracy of major frailty scores. European journal of internal medicine, 23(2), 118-23. doi: 10.1016/j.ejim.2011.09.003

31. Wald NJ, Hackshaw AK, Frost CD. (1999). When can a risk factor be used as a worthwhile screening test? Bmj, 319(7224), 1562-5. 


\section{$\underline{\text { Tables and figures: }}$}

Table 1. Characteristics of the participants in the GAZEL study in 2012 according to their inclusion in the analysis

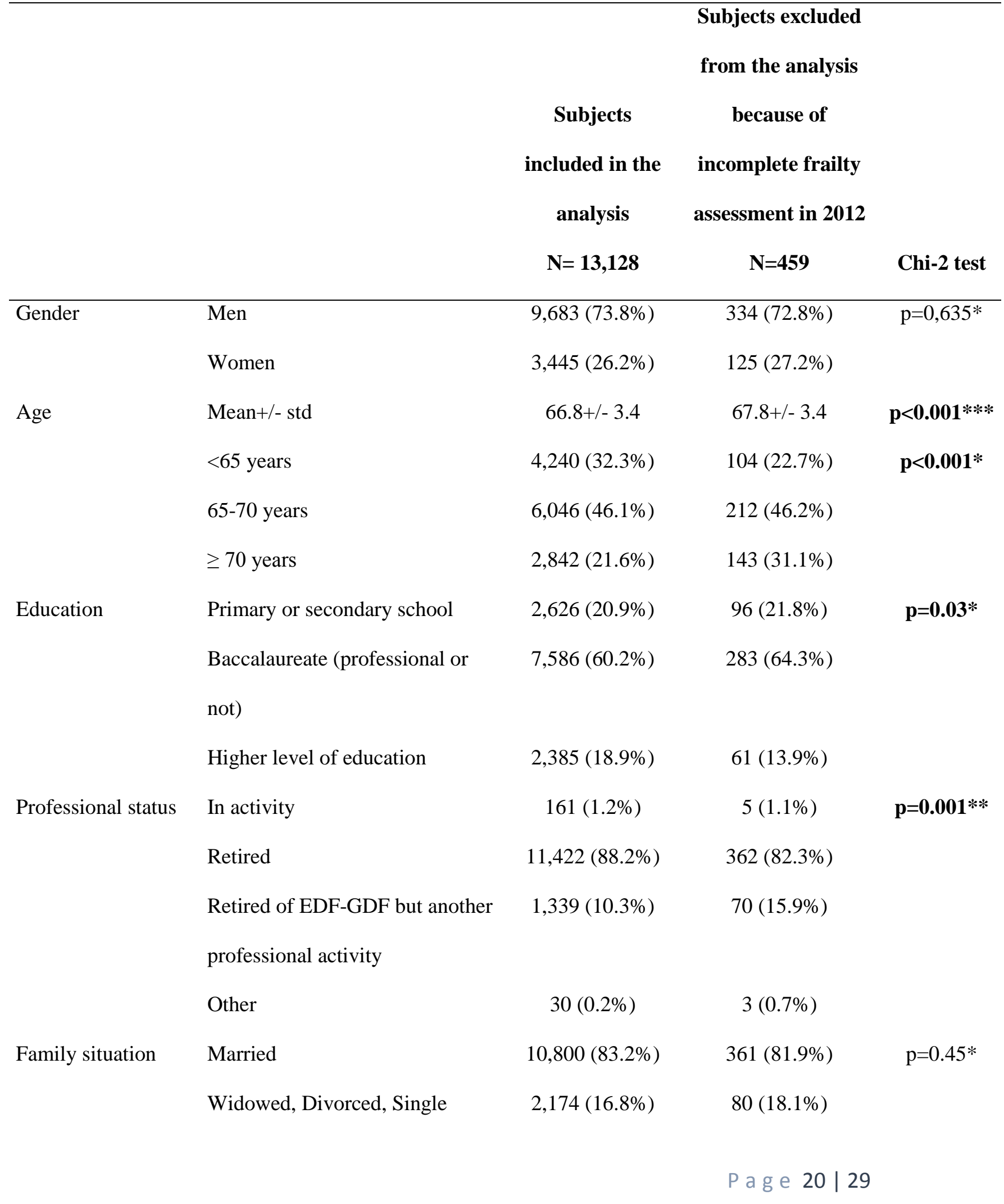




\begin{tabular}{|c|c|c|c|c|}
\hline Perceived social & Disadvantaged & $601(4.9 \%)$ & $22(5.7 \%)$ & $\mathrm{p}=0.44^{*}$ \\
\hline \multirow[t]{2}{*}{ situation } & Normal & $9,849(81.1 \%)$ & $318(82.4 \%)$ & \\
\hline & Comfortable & $1,698(14.0 \%)$ & $46(11.9 \%)$ & \\
\hline Comorbidity score & Mean +/-SD & $1.42+/-1.0$ & $1.44+/-1.0$ & $\mathrm{p}=0.64 * * *$ \\
\hline Body mass index & $\leq 18,5$ & $114(0.9 \%)$ & $3(0.7 \%)$ & $\mathrm{p}=0.94 * *$ \\
\hline \multirow[t]{3}{*}{$\left(\mathrm{kg} / \mathrm{m}^{2}\right)$} & $18,5-25$ & $5,198(40.1 \%)$ & $180(40.8 \%)$ & \\
\hline & $25-30$ & $5,762(44.5 \%)$ & $192(43.5 \%)$ & \\
\hline & $>30$ & $1,884(14.5 \%)$ & $66(15.0 \%)$ & \\
\hline \multirow[t]{3}{*}{ Tobacco } & Non-smoker & $11,511(92.2 \%)$ & $357(91.1 \%)$ & $\mathrm{p}=0.31^{*}$ \\
\hline & Little smoker & $595(4.8 \%)$ & $25(6.4 \%)$ & \\
\hline & Medium - Heavy smoker & $370(3.0 \%)$ & $10(2.5 \%)$ & \\
\hline \multirow[t]{4}{*}{ Alcohol } & Abstinent & $1,940(18.4 \%)$ & $78(25.9 \%)$ & $\mathbf{p}=0.01^{*}$ \\
\hline & Little drinker & $4,714(44.8 \%)$ & $120(39.9 \%)$ & \\
\hline & Medium drinker & $2,746(26.1 \%)$ & $76(25.2 \%)$ & \\
\hline & Heavy drinker & $1,131(10.7 \%)$ & $27(9.0 \%)$ & \\
\hline
\end{tabular}

Abbreviations : * Chi2 test $* *$ Fischer exact test $* * *$ Student test 
Table 2. Prevalence of reported problems or difficulties in items included in the

Strawbridge questionnaire $(\mathbf{n}=13,128)$.

\begin{tabular}{|c|c|c|c|}
\hline \multirow[t]{3}{*}{ - } & \multicolumn{3}{|c|}{ Prevalence of problems or difficulties* } \\
\hline & Whole sample & Men & Women \\
\hline & $n=13,128$ & $n=9,683$ & $n=3,445$ \\
\hline Domain I: Physical function and balance & $1,357(10.3 \%)$ & $792(8.2 \%)$ & $565(16.4 \%)$ \\
\hline Experienced a sudden loss of balance & $342(2.6 \%)$ & $192(2.0 \%)$ & $150(4.4 \%)$ \\
\hline Arm weakness & $652(5.0 \%)$ & $325(3.4 \%)$ & $327(9.6 \%)$ \\
\hline Leg weakness & $655(5.1 \%)$ & $413(4.3 \%)$ & $242(7.2 \%)$ \\
\hline Get dizzy when you rise from a seated position & $420(3.2 \%)$ & $265(2.8 \%)$ & $155(4.5 \%)$ \\
\hline Domain II: Nutritive function & $256(2.0 \%)$ & $145(1.5 \%)$ & $111(3.2 \%)$ \\
\hline Unexplained weight loss & $61(0.5 \%)$ & $35(0.4 \%)$ & $26(0.8 \%)$ \\
\hline Loss of appetite & $230(1.8 \%)$ & $128(1.3 \%)$ & $102(3.0 \%)$ \\
\hline Domain III: Cognitive function & $1,659(12.6 \%)$ & $1,140(11.8 \%)$ & $519(15.1 \%)$ \\
\hline Difficulty finding the right word & $880(6.7 \%)$ & $552(5.7 \%)$ & $328(9.6 \%)$ \\
\hline Difficulty paying attention & $358(2.8 \%)$ & $238(2.5 \%)$ & $120(3.5 \%)$ \\
\hline Difficulty remembering things & $670(5.1 \%)$ & $453(4.7 \%)$ & $217(6.3 \%)$ \\
\hline Forget where you put things & $888(6.8 \%)$ & $618(6.4 \%)$ & $270(7.9 \%)$ \\
\hline Domain IV: Sensory function & $5,462(41.6 \%)$ & $4,181(43.2 \%)$ & $1,281(37.2 \%)$ \\
\hline Difficulty reading a newspaper & $295(2.3 \%)$ & $202(2.1 \%)$ & $93(2.7 \%)$ \\
\hline Difficulty recognizing a friend from across the street & $377(2.9 \%)$ & $248(2.6 \%)$ & $129(3.8 \%)$ \\
\hline Difficulty reading signs at night & $1,556(12.0 \%)$ & $854(8.9 \%)$ & $702(20.6 \%)$ \\
\hline Difficulty hearing on the phone & $1,219(9.4 \%)$ & $957(10.0 \%)$ & $262(7.7 \%)$ \\
\hline Difficulty hearing a normal conversation & $1,552(11.9 \%)$ & $1,295(13.4 \%)$ & $257(7.5 \%)$ \\
\hline Difficulty carrying on a conversation in a noisy room & $4,694(35.9 \%)$ & $3,819(39.6 \%)$ & $875(25.5 \%)$ \\
\hline
\end{tabular}

* Problems or difficulties were defined differently depending on the domain considered: "often" or

"very often" for domains I II III and "some difficulty" or "great deal of difficulty" for domain IV. 
Table 3. Prevalence of frailty according to age and gender

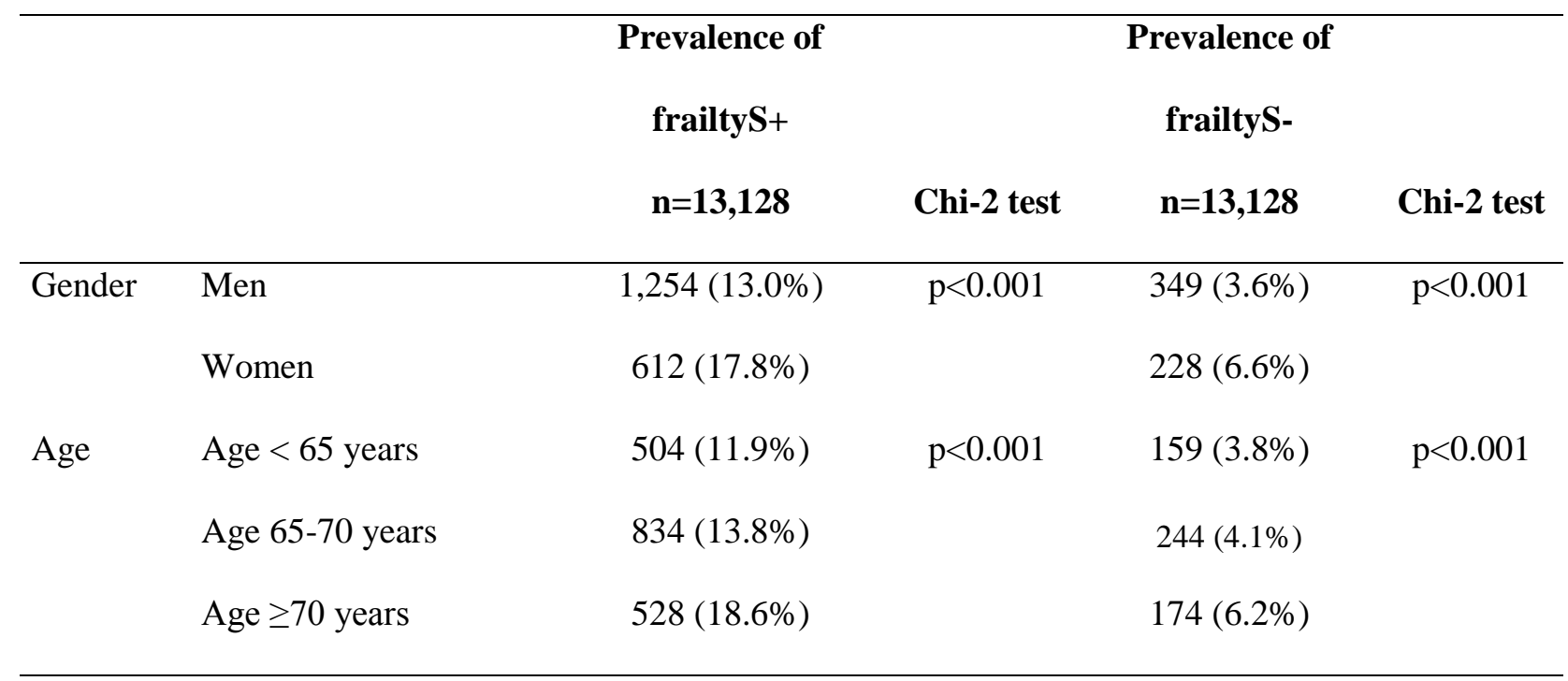

FrailtyS+: definition of frailty including sensory domain; FrailtyS-: definition of frailty excluding sensory domain 
Table 4. Factors associated with frailty in bivariate and multivariate analysis

\begin{tabular}{|c|c|c|c|c|c|c|c|c|c|}
\hline & & \multicolumn{4}{|c|}{ FrailtyS+ } & \multicolumn{4}{|c|}{ FrailtyS- } \\
\hline & & OR & $95 \% \mathrm{CI}$ & aOR & $95 \% \mathrm{CI}$ & OR & $95 \% \mathrm{CI}$ & aOR & $95 \% \mathrm{CI}$ \\
\hline \multirow[t]{2}{*}{ Gender } & Men & 1 & & 1 & & 1 & & 1 & \\
\hline & Women & 1.45 & $1.31-1.61$ & 1.65 & $1.42-1.93$ & 1.89 & $1.60-2.25$ & 2.05 & $1.61-2.60$ \\
\hline \multirow[t]{3}{*}{ Age } & $<65$ years & 1 & & 1 & & 1 & & 1 & \\
\hline & $\geq 65$ and $<70$ years & 1.19 & $1.05-1.34$ & 1.21 & $1.03-1.42$ & 1.08 & $0.88-1.33$ & 1.17 & $0.90-1.52$ \\
\hline & $\geq 70$ years & 1.69 & $1.48-1.93$ & 1.72 & $1.43-2.06$ & 1.69 & $1.35-2.10$ & 1.72 & $1.29-2.31$ \\
\hline \multirow[t]{3}{*}{ Education } & No baccalaureate & 1 & & 1 & & 1 & & 1 & \\
\hline & Baccalaureate & 0.85 & $0.75-0.96$ & 1.10 & $0.93-1.31$ & 0.86 & $0.70-1.06$ & - & - \\
\hline & Higher education & 0.79 & $0.67-0.93$ & 1.35 & $1.08-1.69$ & 0.74 & $0.56-0.97$ & - & - \\
\hline \multirow[t]{5}{*}{ Social situation } & Socially & & & & & & & & \\
\hline & disadvantaged & 2.07 & $1.71-2.51$ & 1.57 & $1.21-2.04$ & 2.02 & $1.49-2.74$ & - & - \\
\hline & Normal & 1 & & 1 & & 1 & & 1 & \\
\hline & Socially & & & & & & & & \\
\hline & comfortable & 0.63 & $0.53-0.75$ & 0.85 & $0.68-1.07$ & 0.55 & $0.39-0.75$ & - & - \\
\hline Body mass index & $\leq 18.5$ & 2.15 & $1.40-3.30$ & 2.08 & $1.19-3.63$ & 4.53 & $2.71-7.54$ & 3.70 & $1.92-7.13$ \\
\hline \multirow[t]{3}{*}{$\left(\mathrm{kg} / \mathrm{m}^{2}\right)$} & between $18.5-25$ & 1 & & 1 & & 1 & & 1 & \\
\hline & between $25-30$ & 0.95 & $0.85-1.06$ & 0.87 & $0.75-1.01$ & 0.91 & $0.75-1.10$ & 0.96 & $0.75-1.23$ \\
\hline & $>30$ & 1.39 & $1.20-1.60$ & 0.87 & $0.72-1.06$ & 1.33 & $1.05-1.69$ & 0.84 & $0.61-1.14$ \\
\hline Alcohol & Abstinent & 1.68 & $1.45-1.94$ & 1.04 & $0.87-1.25$ & 2.36 & $1.89-2.96$ & - & - \\
\hline \multirow[t]{3}{*}{ consumption } & Little drinker & 1 & & 1 & & 1 & & 1 & \\
\hline & Medium drinker & 1.10 & $0.95-1.27$ & 1.03 & $0.87-1.21$ & 0.90 & $0.69-1.17$ & - & - \\
\hline & Heavy drinker & 1.65 & $1.39-1.96$ & 1.61 & $1.31-1.98$ & 1.52 & $1.12-2.05$ & - & - \\
\hline \multirow[t]{2}{*}{ Depression } & No depression & 1 & & 1 & & 1 & & 1 & \\
\hline & Depression & 5.81 & $5.18-6.53$ & 3.19 & $2.73-3.73$ & 9.69 & $8.11-11.59$ & 4.97 & $3.97-6.23$ \\
\hline
\end{tabular}




\begin{tabular}{llcccccccc} 
Score of & 0 & 1 & & 1 & & 1 & & 1 & \\
comorbidity & 1 & 2.02 & $1.65-2.46$ & $\mathbf{1 . 5 8}$ & $1.36-1.84$ & 1.94 & $1.31-2.86$ & $\mathbf{1 . 6 3}$ & $1.26-2.10$ \\
& $\geq 2$ & 4.26 & $3.52-5.16$ & $\mathbf{2 . 0 2}$ & $1.68-2.43$ & 5.44 & $3.76-7.87$ & $\mathbf{2 . 4 5}$ & $1.85-3.26$ \\
\multirow{2}{*}{$\begin{array}{l}\text { Self-perceived } \\
\text { health }\end{array}$} & Very good & 0.30 & $0.25-0.36$ & 0.40 & $0.32-0.50$ & 0.28 & $0.19-0.41$ & 0.44 & $0.29-0.69$ \\
& Good & 1 & & 1 & & 1 & & 1 & \\
& Poor & 3.00 & $2.67-3.37$ & $\mathbf{2 . 0 7}$ & $1.77-2.42$ & 4.55 & $3.78-5.48$ & $\mathbf{2 . 4 2}$ & $1.91-3.06$ \\
& Very poor & 8.92 & $6.28-12.66$ & $\mathbf{3 . 4 0}$ & $2.12-5.47$ & 15.97 & $10.84-23.53$ & $\mathbf{5 . 9 2}$ & $3.60-9.71$
\end{tabular}

aOR: adjusted Odds Ratio

FrailtyS+: frail if 2 impaired domains among physical, nutritive, cognitive and sensory domains

FrailtyS-: frail if 2 impaired domains among physical, nutritive and cognitive domains 
Table 5. Prediction of death, hospitalisation, and onset of difficulties in everyday move according to the frailty definition in the GAZEL cohort

Difficulties in

$\operatorname{Death}^{a}(n=182) \quad$ Hospitalisation $^{b}(n=479) \quad$ everyday move $^{c}(n=703)$

$\begin{array}{llllll}\text { Predictive value } & \text { aHR }[95 \% \text { CI }] \quad \text { Harrell's c } & \text { aOR }[95 \% \text { CI }] & \text { AUC } & \text { aOR }[95 \% \text { CI }] & \text { AUC }\end{array}$

By domain (each

domain adjusted for

the others)

0.7906

0.6511

0.7159

Physical impairment

$1.76[1.10-2.82]$

$1[0.73-1.37]$

3.12 [2.43-4.00]

Nutritive impairment

3.59 [2.00-6.47]

$1.43[0.82-2.49]$

$0.66[0.35-1.28]$

Cognitive impairment

0.77 [0.46-1.31]

1.15 [0.86-1.53]

1.36 [1.07-1.72]

Sensory impairment

0.90 [0.63-1.28]

1.37 [1.12-1.68]

1.37 [1.16-1.63]

According to the frailty

definition

FrailtyS+

1.43 [0.94-2.17]

0.7753

1.31 [1.01-1.70]

0.6453

2.27 [1.83-2.81]

0.7005

FrailtyS-

$2.28[1.32-3.92]$

0.7764

$1.26[0.83-1.90]$

0.6418

2.92 [2.04-4.17]

0.6919

aHR: adjusted hazard ratio; aOR: adjusted odds ratio; CI:confidence interval; AUC:area under the curve

FrailtyS+: frail if 2 impaired domains among physical, nutritive, cognitive and sensory domains

FrailtyS-: frail if 2 impaired domains among physical, nutritive and cognitive domains

${ }^{a}$ Model adjusted for: age, gender, alcohol and tobacco consumption, cancer, depression, antecedents of hospitalisation in last year and other domains of the Strawbridge for the analysis by domain 
${ }^{\mathrm{b}}$ Model adjusted for: age, gender, socio-professional situation, familial status, depression, HTA, cancer, heart pathologies and others domains of Strawbridge questionnaire for the analysis by domain

${ }^{\mathrm{c}}$ Model adjusted for : age, gender, lung disease, diabetes, articular or muscular pain, depression, antecedents of hospitalisation in last year and other domains of the Strawbridge score for the analysis by domain. 
20,625 subjects included in 1989

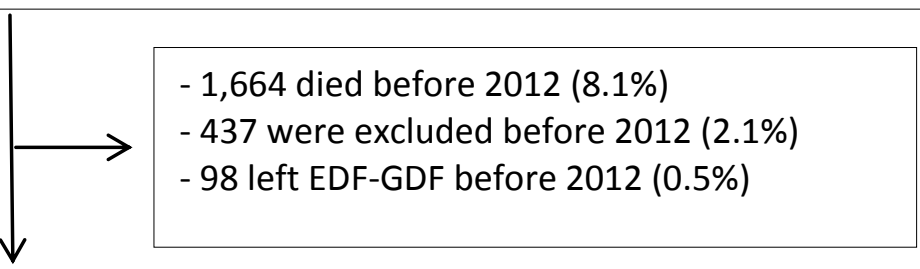

18,426 (89.3\%) subjects still included in the cohort in 2012

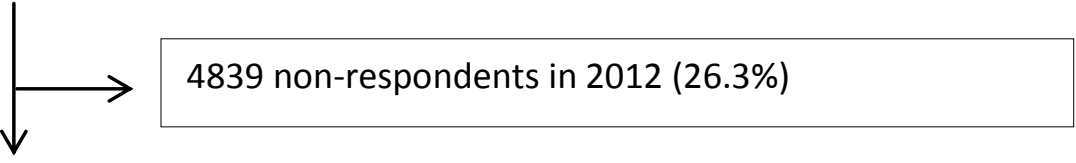

13,587 subjects who returned the questionnaire in 2012 (participation rate $=73.7 \%$ )

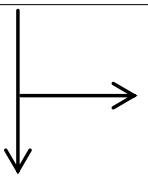

459 were excluded (3.4\%) because of missing data

13,128 subjects included in the study (96.6\%)

- 12,118 with data for the entire Strawbridge score (92.3\%)

- 940 with data in at least one item of each of the 4 domains (7.2\%)

- 70 with missing data among the items of the Strawbridge

questionnaire but with at least 2 impaired domains (0.5\%)

Figure 1. Flow chart of the study 